\title{
Stratospheric tropical warming event and its impact on the polar and tropical troposphere
}

\author{
Kunihiko Kodera $^{1}$, Nawo Eguchi ${ }^{2}$, Hitoshi Mukougawa ${ }^{3}$, Tomoe Nasuno ${ }^{4}$, and Toshihiko Hirooka ${ }^{5}$ \\ ${ }^{1}$ Institute for Space-Earth Environmental Research, Nagoya University, Nagoya, Japan \\ ${ }^{2}$ Research Institute for Applied Mechanics, Kyushu University, Kasuga, Japan \\ ${ }^{3}$ Disaster Prevention Research Institute, Kyoto University, Uji, Japan \\ ${ }^{4}$ Research Institute for Global Change, Japan Agency for Marine-Earth Science and Technology, Yokohama, Japan \\ ${ }^{5}$ Department of Earth and Planetary Sciences, Kyushu University, Fukuoka, Japan \\ Correspondence to: Kunihiko Kodera (kodera@isee.nagoya-u.ac.jp)
}

Received: 24 September 2016 - Published in Atmos. Chem. Phys. Discuss.: 6 October 2016

Revised: 3 December 2016 - Accepted: 13 December 2016 - Published: 12 January 2017

\begin{abstract}
Stratosphere-troposphere coupling is investigated in relation to middle atmospheric subtropical jet (MASTJ) variations in boreal winter. An exceptional strengthening of the MASTJ occurred in association with a sudden equatorward shift of the stratospheric polar night jet (PNJ) in early December 2011. This abrupt transformation of the MASTJ and PNJ had no apparent relation to the upward propagation of planetary waves from the troposphere. The impact of this stratospheric event penetrated into the troposphere in two regions: in the northern polar region and the tropics. Due to the strong MASTJ, planetary waves at higher latitudes were deflected and trapped in the northern polar region. Trapping of the planetary waves resulted in amplification of zonal wave number 1 component, which appeared in the troposphere as the development of a trough over the Atlantic sector and a ridge over the Eurasian sector. A strong MASTJ also suppressed the equatorward propagation of planetary waves, which resulted in weaker tropical stratospheric upwelling and produced anomalous warming in the tropical stratosphere. In the tropical tropopause layer (TTL), however, sublimation of ice clouds kept the temperature change minor. In the troposphere, an abrupt termination of a Madden-Julian Oscillation (MJO) event occurred following the static stability increase in the TTL. This termination suggests that the stratospheric event affected the convective episode in the troposphere.
\end{abstract}

\section{Introduction}

Stratosphere-troposphere dynamical coupling is an important factor for tropospheric weather and climate. The influence of downward penetration of zonal winds from the polar stratosphere, such as the annular modes (Baldwin and Dunkerton, 1999; Thompson and Wallace, 2001) or the polar night jet (PNJ) oscillation (PJO) (Kuroda and Kodera, 1999, 2004; Hitchcock et al., 2013), has been well documented. More recently, the connection between tropospheric weather and changes in planetary wave structure in the polar region, due to reflection or downward propagation in the polar region, has also been reported (Perlwitz and Harnik, 2003; Shaw and Perlwitz, 2013; Kodera et al., 2008, 2013, 2016a). Although stratosphere-troposphere coupling in the tropical region is more controversial, a possible connection has been proposed based on the modulation of deep convective activity by the stratospheric quasi-biennial oscillation (QBO) (Collimore et al., 2003; Liess and Geller, 2012; Yoo and Son, 2016) and sudden stratospheric warming (SSW) (Kodera, 2006; Eguchi and Kodera, 2010; Kodera et al., 2015; Eguchi et al., 2016).

Two types of westerly jet form in the middle atmosphere during winter: the middle atmosphere subtropical jet (MASTJ) and the PNJ around the polar region. The MASTJ is forced primarily by solar ultraviolet (UV) heating in the tropics, whereas the PNJ is associated with long-wave cooling in the polar region. However, planetary waves also interact with these westerly jets and modulate the MASTJ and 
(a)
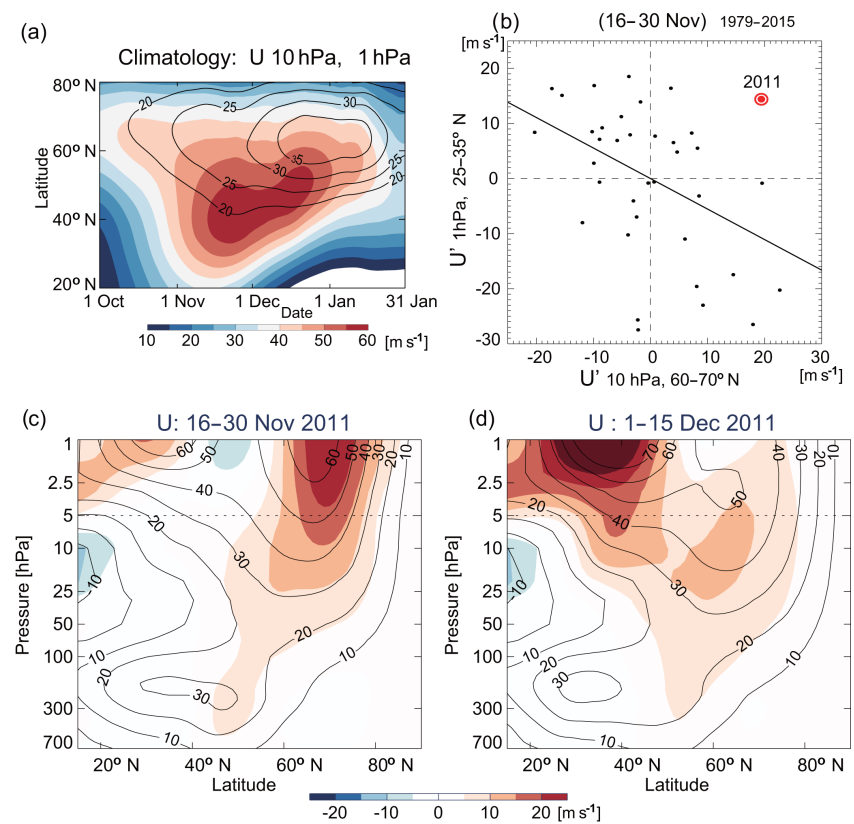

Figure 1. (a) Latitude-time section of the climatological zonalmean zonal wind at $1 \mathrm{hPa}$ (colour shading) and $10 \mathrm{hPa}$ (contours). (b) Scatter diagram of the zonal-mean zonal wind averaged from 16 to 30 November over $25-35^{\circ} \mathrm{N}$ at $1 \mathrm{hPa}$ (ordinate) and $60-70^{\circ} \mathrm{N}$ at $10 \mathrm{hPa}$ (abscissa) for the period 1979-2015. The solid line indicates a regression line. (c) Height-latitude section of the zonalmean zonal wind averaged from 16 to 30 November 2011. Contours and colour shading indicate the climatology and anomalies respectively. (d) Same as (c) but averaged from 1 to 15 December 2011.

PNJ in a complicated way. The climatology of the evolution of the Northern Hemisphere (NH) zonal-mean zonal wind is presented in Fig. 1a from 1 October 2011 to 1 February 2012. The PNJ in the middle stratosphere at $10 \mathrm{hPa}$ increases until January, whereas MASTJ at $1 \mathrm{hPa}$ reaches its maximum around 20 November. After November the MASTJ decreases and shifts poleward.

External forcings in the stratosphere can affect the troposphere through the above-mentioned stratospheretroposphere coupling processes. For instance, a stratospheric ozone depression can produce surface pressure change through modulation of the Southern Hemisphere (SH) annular mode (SAM) (Thompson and Solomon, 2002; Marshall et al., 2004; Polvani et al., 2011). The 11-year solar cycle also affects the surface through modulation of the annular mode or PJO in the NH winter stratosphere (Kodera et al., 2016b). However, the solar signal does not appear in the SAM (Lu et al., 2011; Kodera et al., 2016b). Instead, MASTJ, which is usually maximized around $30^{\circ}$ latitude and $0.5 \mathrm{hPa}$, extends downward into the stratosphere in the SH (Kodera et al., 2016b). It has been suggested that the MASTJ, related to the solar cycle, modulates stratospheric mean meridional circulation, which further influences convective activity in the tropical troposphere (Kodera, 2004; Kodera and Shibata,
2006). On the other hand, it has been pointed out that the MASTJ may be important for the formation of a kind of dynamical instability in the extratropical mesosphere (Iida et al., 2014).

The role of MASTJ in stratosphere-troposphere coupling is poorly understood. The MASTJ in the SH stratopause region strengthens until nearly winter solstice, whereas in the $\mathrm{NH}$ the MASTJ starts to decay earlier before the winter solstice (Kodera and Kuroda, 2002). When the upward propagation of planetary waves increases in mid-winter in the $\mathrm{NH}$, mesospheric MASTJ shifts poleward and weakens (Dunkerton, 2000). Therefore, downward extension of the MASTJ in the NH winter circulation has not attracted attention. In early December 2011, however, an exceptionally rapid downward extension of the MASTJ from the lower mesosphere to the bottom of the stratosphere occurred. Such a sudden change enables us to investigate the evolution of downward penetration. In the present study, we investigate this particular event that produced global tropospheric impacts in the northern polar region as well as in the tropics.

The remainder of the paper is organized as follows. The data are described in Sect. 2, and the results of an analysis of stratosphere-troposphere coupling during NovemberDecember 2011 are presented in Sect. 3. The stratospheric processes producing a strong MASTJ in the stratosphere are first presented in Sect. 3.1. Stratosphere-troposphere coupling is realized by two different processes. In the $\mathrm{NH}$ extratropics, coupling occurs through change in planetary wave propagation, while in the tropics, tropospheric deep convection responds to change in the static stability of the tropical tropopause layer (TTL) induced by the stratospheric mean meridional circulation. These processes are presented in Sect. 3.2.1 and 3.2.2 respectively. For intraseasonal variability in the tropics, the Madden-Julian Oscillation (MJO) (Madden and Julian, 1972) is a typical phenomenon. We briefly argue plausible influence of the rapid downward extension of the MASTJ on MJO activity.

\section{Data}

In this study we use meteorological reanalysis datasets produced by the Japan Meteorological Agency, JRA-55 (available from the web page http://jra.kishou.go.jp/JRA-55/ index_en.html) (Kobayashi et al., 2007). Unless otherwise specified, anomalies are defined as departures from the 37year climatological mean (1979-2015). The data have a horizontal resolution of $1.25^{\circ}$ by $1.25^{\circ}$ and 37 vertical levels, of which 10 levels are above $100 \mathrm{hPa}$ with a top at $1 \mathrm{hPa}$. Cloud fraction data in the TTL are derived from the Cloud Layer Product (Level-2, ver. 3.01) from the Cloud-Aerosol LIdar with Orthogonal Polarization (CALIOP) aboard the CALIPSO satellite (Winker et al., 2007). We also use ice water content data measured by the Earth Observing System/Microwave Limb sounder (EOS/MLS) (Level-2, 
ver.4.2x) (Livesey et al., 2015) at $146 \mathrm{hPa}$. Daily data on a $2.5^{\circ}$ (latitude) by $2.5^{\circ}$ (longitude) grid are first derived from the orbital data. Outgoing long-wave radiation (OLR) data provided by NOAA (e.g. Arkin and Ardanuy, 1989) are used to analyse convective activity in the tropics. The Tropical Rainfall Measuring Mission (TRMM) daily integrated precipitation data (TRMM 3B42 v7) are used to study surface precipitation (Huffman et al., 2007).

\section{Results}

\subsection{Stratospheric event}

To show a particular characteristic of the interannual variation of the MASTJ and PNJ, Fig. 1b presents a scatter diagram of zonal-mean zonal wind in the subtropical stratopause region $\left(25-35^{\circ} \mathrm{N}, 1 \mathrm{hPa}\right)$ and polar stratosphere $\left(60-70^{\circ} \mathrm{N}\right.$, $10 \mathrm{hPa}$ ) during a period of high velocity of the MASTJ (1630 November) for the period 1979-2015. There is a negative correlation such that stronger MASTJ is associated with weaker PNJ and vice versa. In the case of the 2011 winter (red circle, Fig. 1b), however, the MASTJ and PNJ were both strong. This exceptional situation at the end of November (Fig. 1c) soon dissolved during the following period (115 December) by transforming into the more usual structure of a stronger MASTJ accompanied by a relatively weak PNJ (Fig. 1d). To illustrate the circulation change around 4 December, differences between the two 10-day means of zonalmean zonal wind and temperature are shown in Fig. 2. The change in zonal wind appears as a deep seesaw between the MASTJ and the PNJ extending across the whole stratosphere from the stratopause to the tropopause. An important change in the temperature field occurs as warming in the tropics accompanied by cooling in mid-latitudes of the $\mathrm{NH}$, consistent with the strengthening of the MASTJ. The tropical warming extends farther southward into the summer hemisphere, down to $45^{\circ} \mathrm{S}$. In addition, a narrow warming region around the North Pole occurs in association with a decrease of the PNJ.

The evolution of zonal-mean zonal wind during November-December 2011 is illustrated in Fig. 3c. The MASTJ at $1 \mathrm{hPa}$ (colour shading) shows a continuous increase from mid-November to December, while the PNJ at $5 \mathrm{hPa}$ (contours) does not increase in November and largely decreases after 4 December. Vertical sections of zonal winds around $60-70^{\circ} \mathrm{N}$ and $35-45^{\circ} \mathrm{N}$ are shown in Fig. 3d and e respectively. Zonal winds in the subtropics largely increase from 4 December, while the PNJ decreases thereafter. The weakening of the PNJ is delayed at lower altitudes (Fig. 3d). This delay suggests that the interaction between the MASTJ and PNJ starts at upper levels and gradually extends downward. The increase of MASTJ in the middle and lower stratosphere involves an equatorward shift of the PNJ (Fig. 3c).

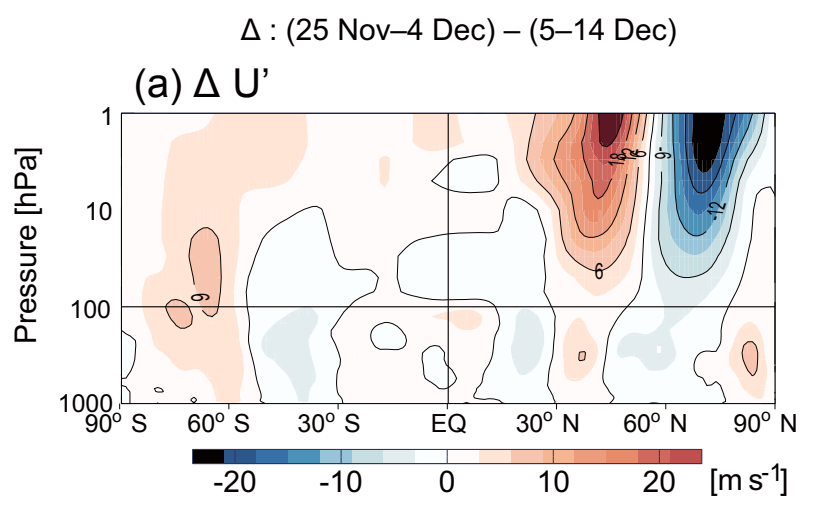

(b) $\Delta \mathrm{T}^{\prime}$

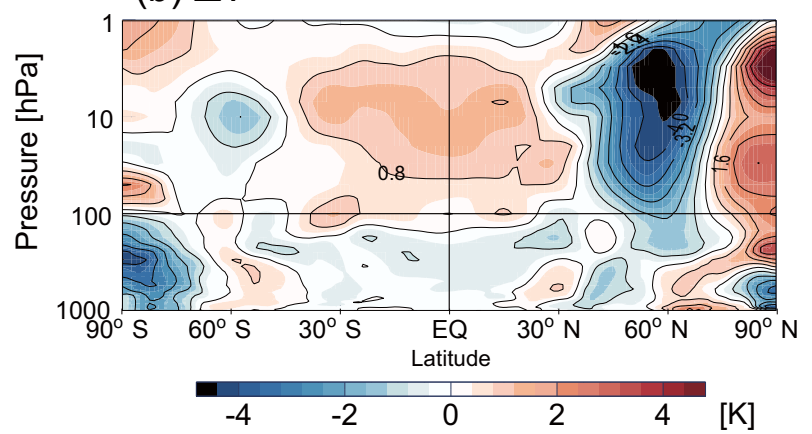

Figure 2. Difference between the mean values from 25 November to 4 December 2011 and from 5 to 14 December 2011 for (a) anomalous zonal-mean zonal wind and (b) anomalous zonalmean temperature.

Simultaneous changes are also found in the stratospheric planetary wave field. Figure $3 \mathrm{~b}$ shows zonal asymmetric components of geopotential height averaged over $60-70^{\circ} \mathrm{N}$ at $10 \mathrm{hPa}$. The amplitude of the planetary waves is small during November, but a ridge and trough develop from early December around $180^{\circ}$ and $0^{\circ}$ longitudes respectively, which makes a wave number 1 feature more conspicuous. This modification of wave structure at $10 \mathrm{hPa}$ suggests a change in propagation property in the stratosphere. The amplification of the stratospheric wave in early December is not related to an increase in the eddy heat flux at $100 \mathrm{hPa}$ averaged over $45-75^{\circ} \mathrm{N}$, a measure of the vertical propagation of planetary waves from the troposphere (Fig. 3a). This indicates that the transition of the circulation at the beginning of December has a middle atmospheric rather than tropospheric origin. The eddy heat flux at $100 \mathrm{hPa}$ strongly increases after 17 December, leading to a minor warming in the upper stratosphere, and both the MASTJ and PNJ weaken towards the end of December (Fig. 3c). The impact of this event is not limited to the extratropics. Changes in the zonal-mean zonal wind are associated with modification of the meridional circulation. Figure $3 \mathrm{f}$ shows zonal-mean anomalous pressure vertical velocity in the tropical region $\left(20^{\circ} \mathrm{S}-20^{\circ} \mathrm{N}\right)$ of the middle stratosphere. Here, the term "anomalous" means deviation from a climatological mean (1979-2015). Anoma- 

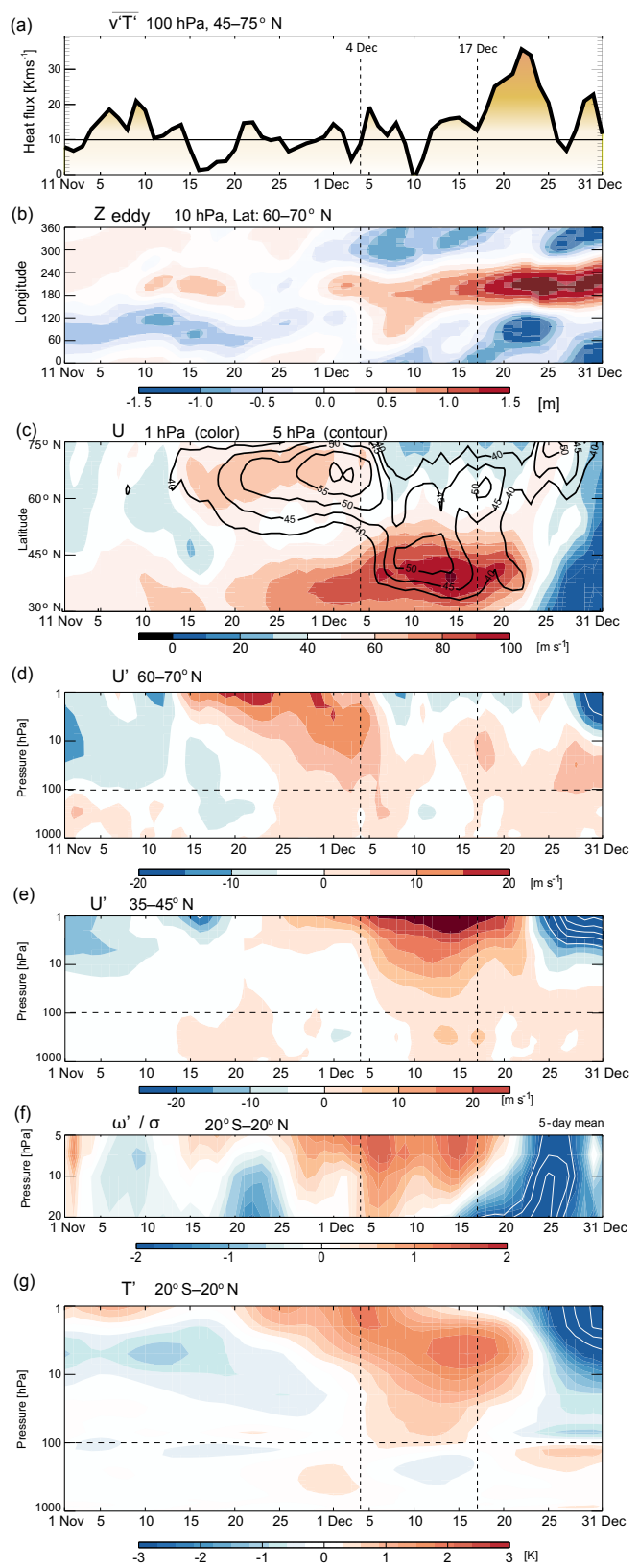

Figure 3. (a) Eddy heat flux at $100 \mathrm{hPa}$ averaged over $45-75^{\circ} \mathrm{N}$. (b) Zonally asymmetric component of the geopotential height averaged over $60-70^{\circ} \mathrm{N}$ at $10 \mathrm{hPa}$. (c) Latitude-time section of zonalmean zonal wind at $1 \mathrm{hPa}$ (colour shading) and $5 \mathrm{hPa}$ (contours). (d) Height-time section of anomalous zonal-mean zonal winds averaged over $60-70^{\circ}$ N. (e) Same as (d) but for zonal wind averaged over $35-45^{\circ} \mathrm{N}$. (f) Anomalous vertical pressure velocity averaged over $20^{\circ} \mathrm{S}-20^{\circ} \mathrm{N}$. For (f), a 5-day running mean was applied. (g) Same as (f) but for temperature. Analysis period is from 1 November to 31 December 2011, and the time mean field during the period is further subtracted from anomalies in (f) and (g). Vertical lines indicate 4 and 17 December with periods of tropical warming in the lower stratosphere. lous downwelling develops concurrently with strengthening of the MASTJ from 4 to 17 December (Fig. 3f). This change manifests as a warming in the tropical stratosphere down to the tropopause (Fig. 3g). Note that the tropical upper troposphere shows a slight cooling during this period.

\subsection{Impact on the troposphere}

\subsubsection{Extra tropics}

The bottom panels of Fig. 4 show 5-day mean zonal-mean zonal wind and the Eliassen-Palm (E-P) flux (e.g. Andrews et al., 1987) from the end of November to early December, corresponding to a period of rapid transformation of the stratospheric westerly jet. The time tendency of the zonalmean zonal wind in the upper stratosphere is displayed in the top panels. The time tendency of zonal mean wind $(U)$ on day $n$ is calculated from the difference between the 3day mean before and after day $n$ as $\Delta U_{n}=\left[\left(U_{n+3}+U_{n+2}+\right.\right.$ $\left.\left.U_{n+1}\right) / 3-\left(U_{n-3}+U_{n-2}+U_{n-1}\right) / 3\right] / 4$.

In spite of the increasing upward component of E-P flux in the lower stratosphere around the core of the PNJ from the end of November to the beginning of December, the subtropical westerly jet in the upper stratosphere-stratopause region continued to grow, although the PNJ in the stratopause region decreased. This suggests a rather passive role of the upward propagation of planetary wave on the evolution of westerly winds in the subtropical stratopause. Acceleration of subtropical zonal wind in the upper stratosphere on 28 November could have resulted from unresolved wave (gravity waves) forcing, and/or increased mean meridional circulation due to diabatic heating. Planetary waves in the stratosphere converge more at higher latitudes in December since the equatorward propagation tends to be hindered by stronger MASTJ. This leads to a large deceleration of the PNJ and a suppression of the upward propagation of planetary waves in the polar region around 8 December. Accordingly, waves in the polar region are trapped in the stratosphere.

Change in the planetary wave propagation in the polar region can also be seen in the evolution of the vertical wave structure. Figure 5a shows height-longitude sections of the zonally asymmetric component of geopotential height averaged over $60-70^{\circ} \mathrm{N}$. When the PNJ was strong on 28 November, waves propagated upward from the troposphere guided by the PNJ (Matsuno, 1970). The planetary waves propagate upward as a wave packet composed of multiple zonal wave number components (Hayashi, 1981). Upward propagation can be seen as a westward tilted ridge and trough lines with increasing altitude over the Eurasian sector (Fig. 5a). In the upper stratosphere, waves are deflected equatorward due to the stronger PNJ. Therefore, the wave amplitude in the upper stratospheric polar region was small at the end of November. On 3 December, the wave amplitude increased in the upper stratosphere. The westward tilt of trough and ridge lines was 

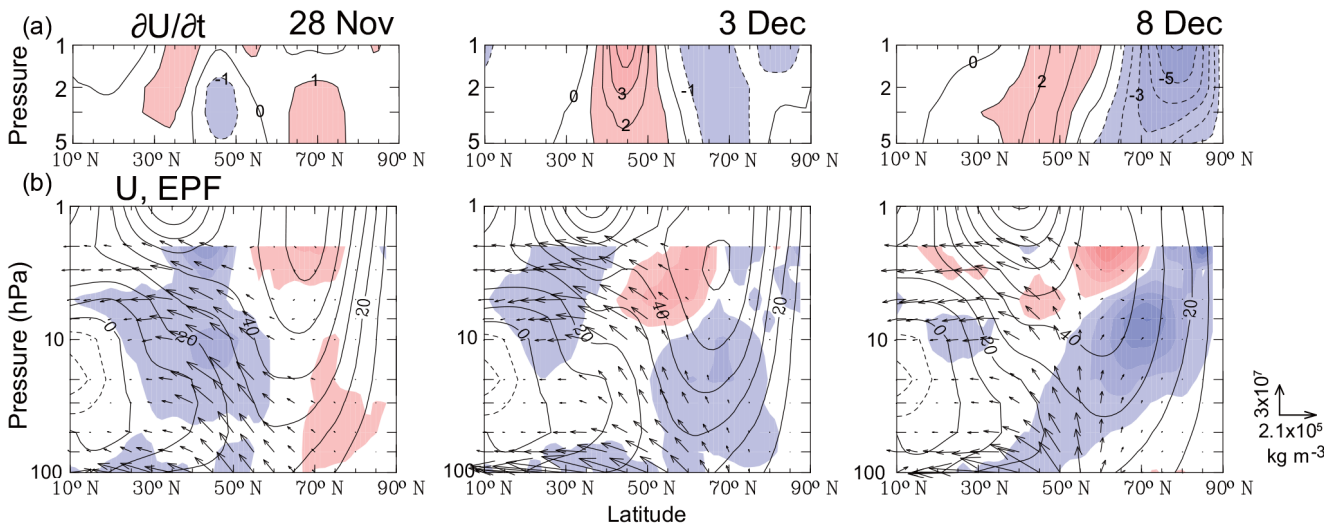

$\begin{array}{llllllllll}-7 & -5 & -3 & -1 & 1 & 3 & 5 & 7 & {\left[\mathrm{~ms}^{-1} \mathrm{day}^{-1}\right]}\end{array}$

Figure 4. (a) Zonal-mean zonal wind tendency $\left[\mathrm{ms}^{-1} \mathrm{day}^{-1}\right]$. (b) E-P flux (arrows) and zonal-mean zonal winds (contours) that are 5day-averaged. E-P flux divergences are also shown using colour shading. The dates from left to right (28 November, 3 December, and 8 December) are the middle days of the 5-day mean.
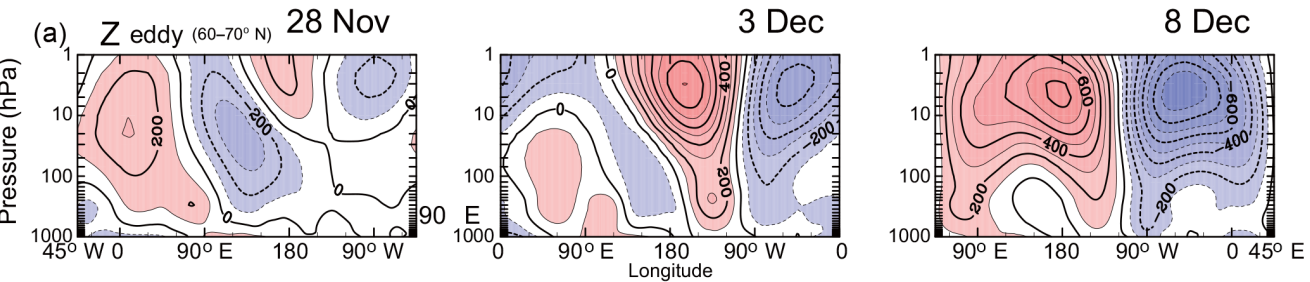

(b) Z500
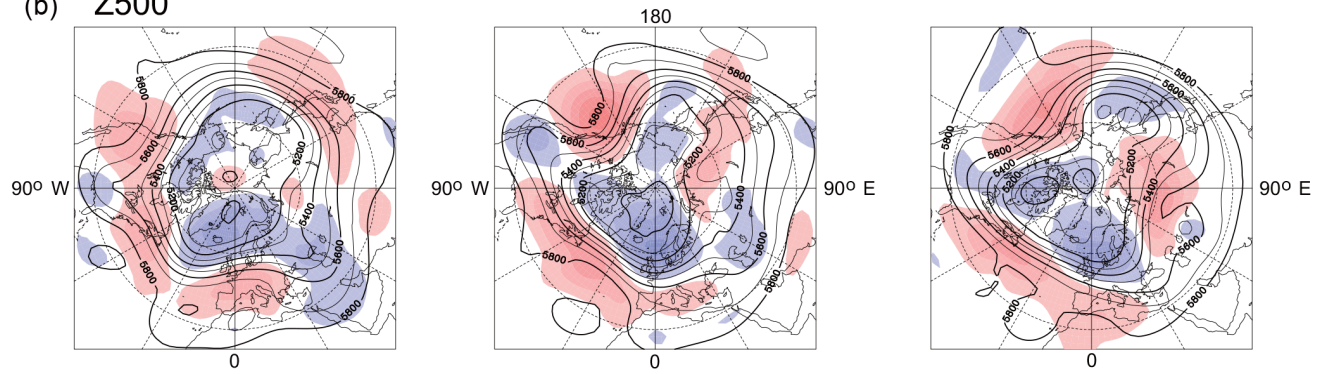

$-280-200-120 \quad-40 \quad 40 \quad 120 \quad 200 \quad 280 \quad(m)$

Figure 5. (a) Latitude-height section of the 5-day-mean zonally asymmetric component of geopotential height (m) averaged over 60-70 ${ }^{\circ} \mathrm{N}$. The origin of the longitude shifts eastward with time: $45^{\circ} \mathrm{W}, 0^{\circ}$, and $45^{\circ} \mathrm{E}$ from left to right. (b) The 5-day-mean 500 hPa geopotential height (contours) and deviation from the climatology (colour shading). The analysis period is the same as in Fig. 4.

still conspicuous over the Eurasian sector, indicating the persistent upward propagation in the sector; however, the trough line tilted eastward over the Atlantic sector. Thus, the wave in the polar region was trapped and deflected in the upper stratosphere and propagated downward into the Atlantic sector. When the PNJ further weakened and the MASTJ became stronger on 8 December, the upward propagation of the planetary waves was largely suppressed. The standing wave feature (i.e. little phase tilt in the vertical) indicates that the amplification of the wave number 1 component occurred due to interference between the upward and downward propagating waves. The impact on the troposphere can be seen in the $500 \mathrm{hPa}$ geopotential height (Fig. 5b). Because the wave activity was low, meandering was weak on 28 November. When wave number 2 components were trapped in the middle stratosphere, a ridge developed over the North Pacific on 3 December. Finally, amplification of the wave number 1 component resulted in the development of a trough over the Atlantic sector and a ridge over the Eurasian sector, forming a blocking over the Eurasian continent.

\subsubsection{Tropics}

To investigate the downward penetration of stratospheric variation in the equatorial $\mathrm{SH}$, time-height sections (averaged over the Equator to $20^{\circ} \mathrm{S}$ ) of zonal-mean temperature 

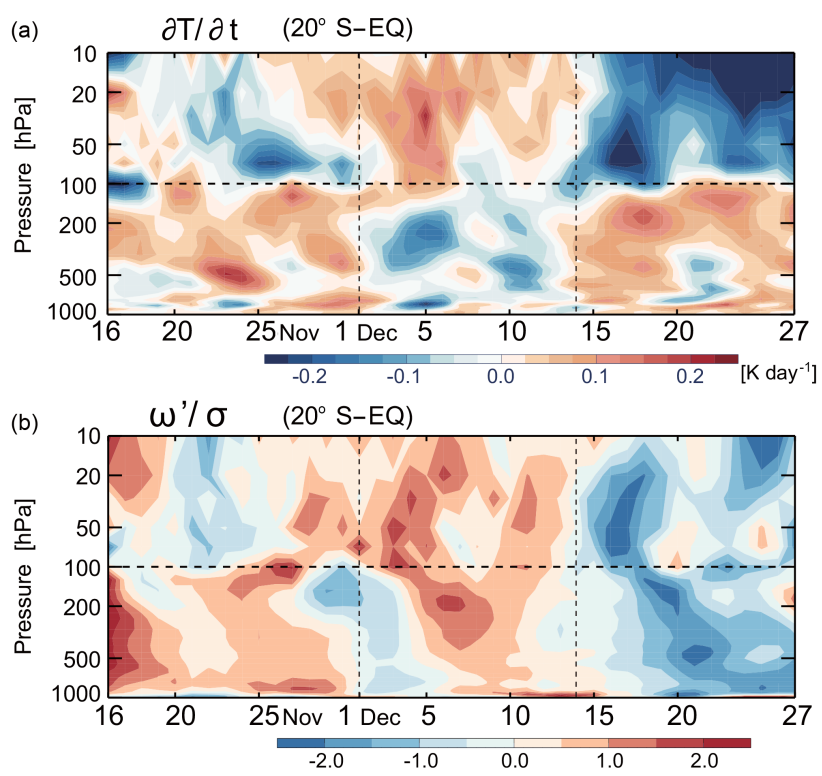

(c) Ice water content $146 \mathrm{hPa}$

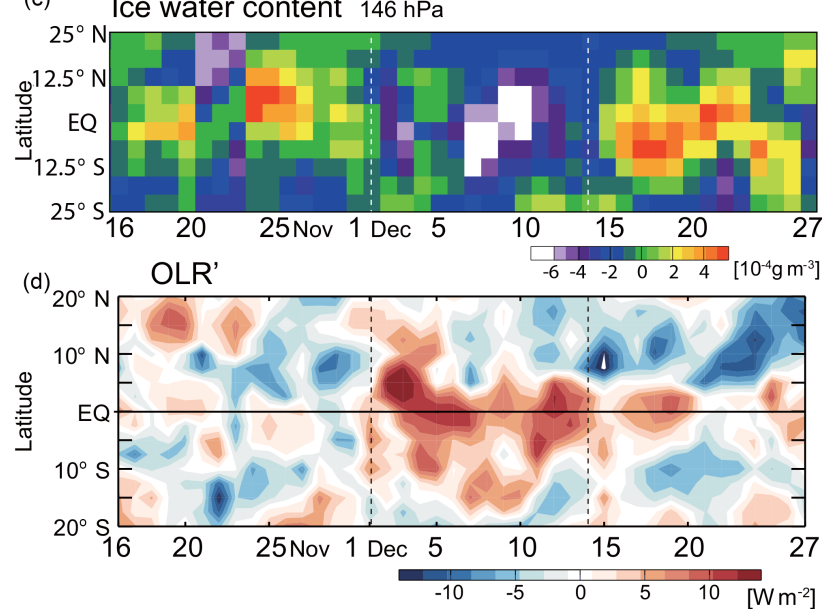

(e)

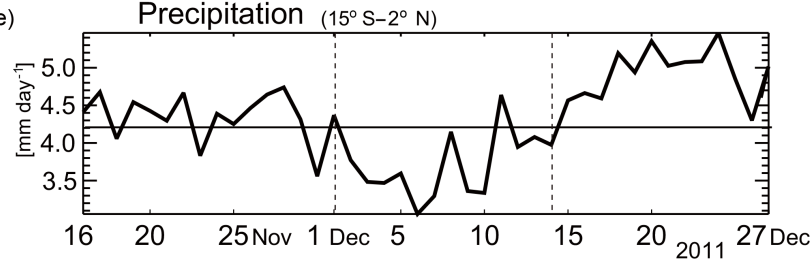

Figure 6. (a) Height-time section of zonal-mean temperature tendency averaged from $20^{\circ} \mathrm{S}$ to the Equator. (b) Same as (a) but for a 3-day running mean of the anomalous vertical pressure velocity normalized by the daily standard deviation. (c) Latitude-time section of ice water content at $146 \mathrm{hPa}$, of which linear tendency has been subtracted. (d) Same as (c) but for anomalous OLR. (e) Surface precipitation averaged from $15^{\circ} \mathrm{S}$ to $2^{\circ} \mathrm{N}$, as estimated from TRMM.

tendency and normalized 3-day mean vertical pressure velocity are shown in Fig. 6a and b respectively. An increase in temperature tendency in early December is apparent at levels higher than $100 \mathrm{hPa}$ (Fig. 6a). The upper tropospheric temperature tendency is opposite to that in the lower stratosphere. The variation of the temperature tendency corresponds well to that of the standardized pressure vertical velocity within the stratosphere (Fig. 6b). However, unlike the negative temperature tendency, the positive anomaly of vertical pressure velocity extended farther into the troposphere after around 4 December, which coincided with a period of decreased ice water content in the TTL (Fig. 6c).

The changes in vertical velocity in the lower stratosphere lead the temperature change (Fig. $3 \mathrm{~g}$ ) by $\sim 3$ days, starting and ending around 1 and 14 December (vertical lines in Fig. 6).

When considering the lower tropospheric temperature tendency, the adiabatic heating produced by anomalous downwelling is compensated for by the sublimation of ice cloud, and therefore the temperature does not increase in the upper troposphere. The decrease in convective activity in the troposphere over the equatorial $\mathrm{SH}$ is also indicated by positive anomalies in OLR (Fig. 6d). As the precipitation also decreases (Fig. 6e), both clouds in the upper troposphere and deep convective clouds decrease during this period. These changes are opposite to those observed during the cooling phase in the tropical stratosphere related to SSW events (Eguchi et al., 2015; Kodera et al., 2015). In fact, after 15 December 2011, opposite changes in the tropics are seen that are associated with the occurrence of a minor SSW event (Fig. 6): the tropical stratospheric temperature decreased (Fig. 6a), ice clouds became abundant in the TTL (Fig. 6c), and precipitation increased at the surface (Fig. 6e).

Changes in the TTL during the tropical stratosphere warming event are depicted in Fig. 7. Consecutive 7-day mean height-latitude sections are calculated for (a) anomalous temperature, (b) cirrus cloud frequency, and (c) vertical velocity during the periods of (i) 24-30 November, (ii) 1-7 December, and (iii) 8-14 December. For a clearer view of the vertical extent of the tropospheric upwelling in the TTL, vertical pressure velocity is converted to vertical velocity in Fig. 7c. To illustrate the evolution of the vertical temperature gradient in the TTL, anomalous temperature in Fig. 7a is shown as the difference between each pressure level and $200 \mathrm{hPa}$. Descent of warm anomalies from the lower stratosphere to the TTL is clearly seen through these periods. Cirrus clouds largely decrease in the equatorial TTL, and a weakening of upwelling (corresponding to a strengthening of anomalous downwelling in Fig. 6b) is seen in the troposphere during period (ii). Suppression of upwelling continues in the SH during period (iii), while some recovery is seen in the NH. This difference creates some meridional asymmetry, which is also evident in the cloud field.

To show the horizontal structure, anomalous OLR is presented for the same three periods in Fig. 8. An intense convective centre is located over the Indian Ocean at the end of November (i in Fig. 8). This centre of action moves eastward over the Maritime Continent and then weakens (ii). During period (iii) when upwelling in the equatorial $\mathrm{SH}$ troposphere 

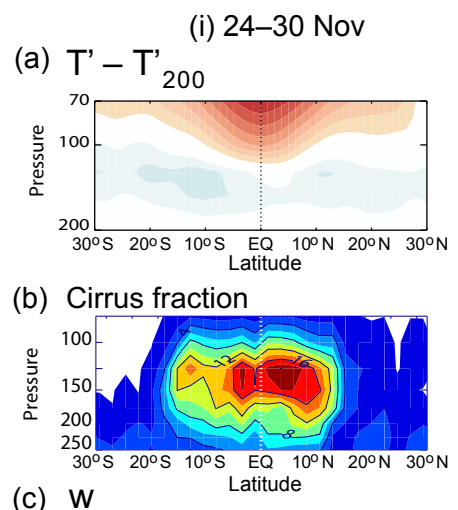

(ii) 1-7 Dec
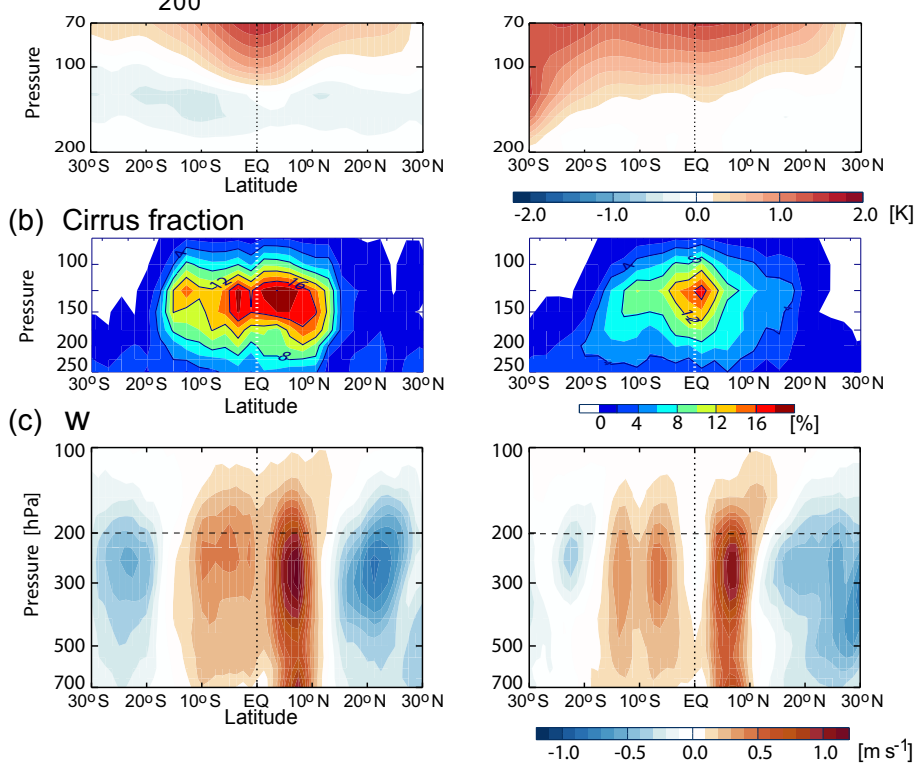

(iii) 8-14 Dec
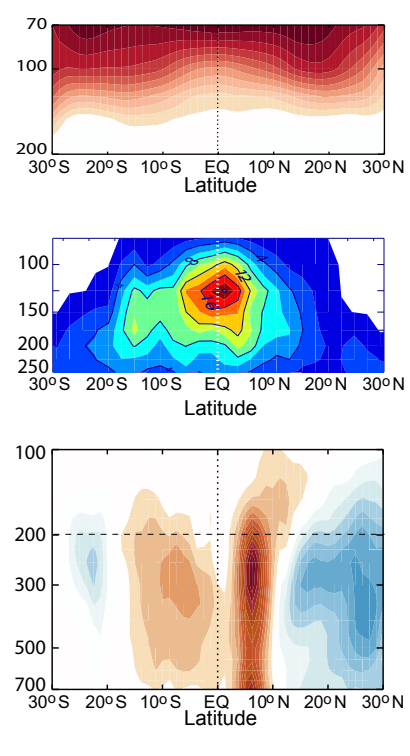

Figure 7. Consecutive 7-day-mean height-latitude sections: (i) 24-30 November, (ii) 1-7 December, and (iii) 8-14 December. (a) Anomalous temperature difference between each pressure level and $200 \mathrm{hPa}$. (b) Cirrus cloud frequency and (c) vertical velocity.
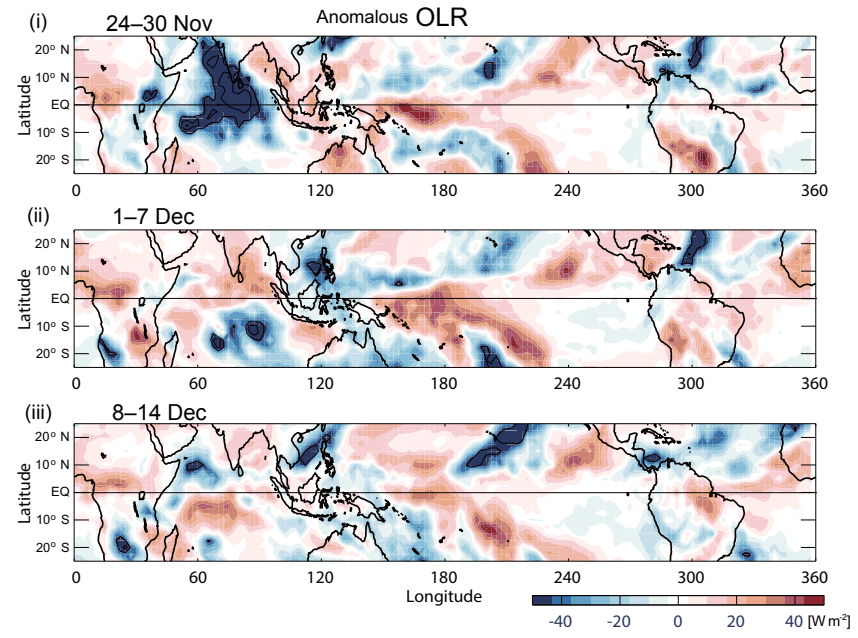

Figure 8. Same as Fig. 7 but for latitude-longitude sections of OLR anomalies.

is suppressed, positive anomalies in OLR expand over the Indian Ocean. Conversely, negative anomalies are distributed more zonally in the tropical $\mathrm{NH}$.

The current analysis period is included in the field experiment "CINDY/DYNAMO" campaign to collect in situ atmospheric and oceanic data to study MJO over the equatorial Indian Ocean (Yoneyama et al., 2013). One of the characteristics of the tropical circulation during this boreal autumn-winter is that the MJO was particularly active (e.g. Nasuno, 2013). An MJO event in 2011 started on 17 Septem-

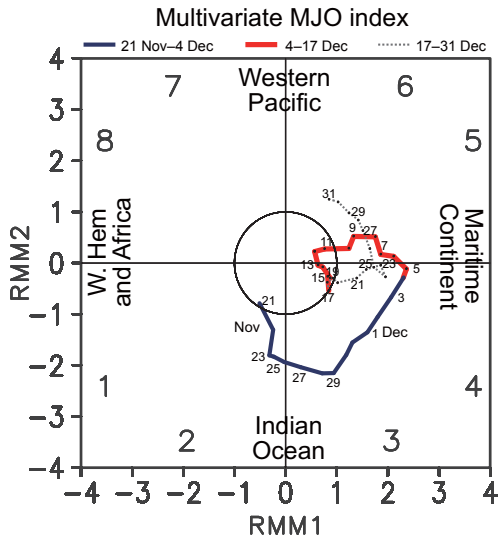

Figure 9. Phase diagram of the multivariate MJO index from 21 November to 31 December 2011.

ber and ended on 8 December according to Gottschalck et al. (2013). The phase diagram of the multivariate MJO index of Wheeler and Hendon (2004), from 21 November to 31 December 2011, is presented in Fig. 9. The period of tropical warming in the lower stratosphere from 4 to 17 December in Fig. 1 is indicated by solid red lines. The periods before and after are indicated by solid dark blue lines and dashed black lines respectively. Eastward propagation of the MJO is apparent during November 2011. The MJO suddenly weakens in the Maritime Continent region around 8 December. This disruption of the MJO follows the enhanced equatorial anomalous downwelling in the troposphere (Fig. 7b). 


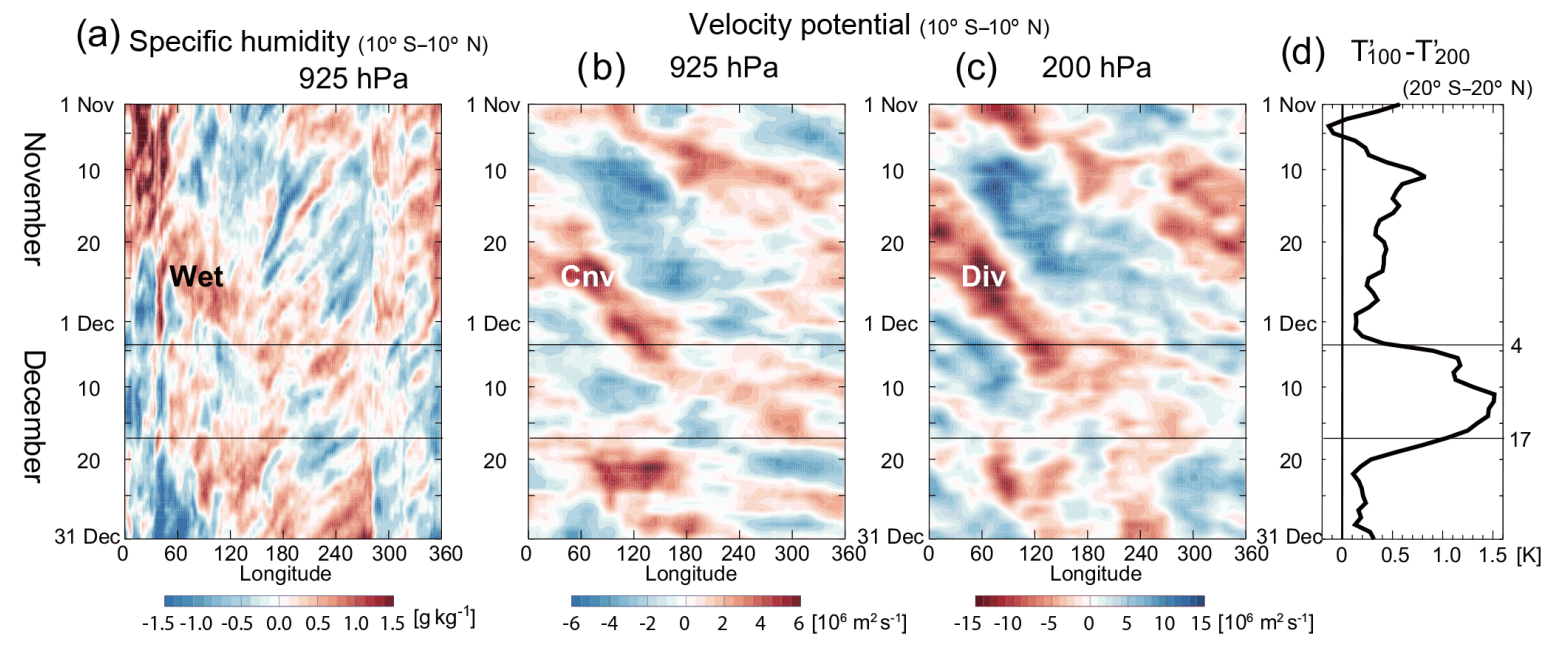

Figure 10. Time-longitude section around the equator $\left(10^{\circ} \mathrm{S}-10^{\circ} \mathrm{N}\right)$ during November to December 2011 for (a) anomalous-specific humidity, (b) anomalous velocity potential at $925 \mathrm{hPa}$, (c) anomalous velocity potential at $200 \mathrm{hPa}$, and (d) difference in anomalous temperature between 100 and $200 \mathrm{hPa}$. Time mean values during the analysed period are subtracted from climatological anomalies. "Wet", "Cnv", and "Div" indicate wet, convergent, and divergent zones respectively. Horizontal lines mark 4 and 17 December, similar to Fig. 3.

The multivariate index is a combination of three different variables (OLR and zonal winds at 850 and $200 \mathrm{hPa}$ ). Figure $10 \mathrm{a}$ and $\mathrm{b}$ show specific humidity and velocity potential at $925 \mathrm{hPa}$ respectively, averaged around the equator $\left(10^{\circ} \mathrm{S}-\right.$ $10^{\circ} \mathrm{N}$ ) during November to December 2011. The eastward propagation of the convergent area (positive anomaly of the velocity potential) following an increase of anomalous water vapour is observed in December and November in the lower troposphere. The MJO is characterized by a convergence zone in the lower level and a divergence zone above. At $200 \mathrm{hPa}$ (Fig. 10c), the divergent (negative anomaly) area propagates eastward in November, similar to the $925 \mathrm{hPa}$ level. To facilitate the comparison with the lower level, negative values are shown by warm colours at $200 \mathrm{hPa}$. The divergent area at $200 \mathrm{hPa}$ does not propagate eastward after $8 \mathrm{De}-$ cember and disappears over the eastern Pacific, in spite of the conditions being favourable to maintain the convective activity, such as an increase in convergence at $925 \mathrm{hPa}$ (Fig. 10b) and an increase in moisture (Fig. 10a). Anomalous static stability in the TTL is presented in Fig. 10d as the difference between the temperature at 100 and $200 \mathrm{hPa}$. An increase in stability in the TTL (after 4 December) is concurrent with the termination of the MJO.

\section{Discussion and concluding remarks}

In the present study, we investigated circulation changes related to the formation of a strong MASTJ in the stratosphere in November-December 2011. The event started from the mesosphere, penetrated to the troposphere in the polar region as well as in the tropics, and involved diverse amplifying processes. During November 2011, the MASTJ and
PNJ were both strong around the stratopause region. Usually, the MASTJ shifts poleward and becomes weaker when the planetary wave activity increases with the seasonal march (Fig. 1a). However, in the case of December 2011, the stratospheric PNJ abruptly shifted equatorward before the poleward shift of the MASTJ (Fig. 3c), which was a unique event. This sudden change in the MASTJ and PNJ was not closely related to the tropospheric forcing change. Since meridional zonal wind shear in the tropics has a large impact on the propagation of planetary waves (Yoden and Ishioka, 1993), a strong MASTJ and weak PNJ tend to deflect the equatorward propagation of planetary waves in the upper stratosphere. This deflection would further accelerate the MASTJ and decelerate the PNJ due to decreased and increased convergence of E-P flux in the tropics and polar region respectively. Concurrent temperature change occurred in the $\mathrm{NH}$ stratosphere (Fig. 2b), with warming in the tropics and cooling in mid-latitudes of the entire stratosphere, consistent with the thermal wind balance. These circulation changes in the stratosphere had a significant impact on the troposphere.

The exceptional event in early winter 2011-2012 may be attributed to a strong MASTJ and PNJ in November. The strong PNJ may have resulted from weak wave forcing in the troposphere (Fig. 3a). However, the strong MASTJ coexisted with an enhanced PNJ in November 2011, which is an unusual situation (Fig. 1b). As the top level of the JRA-55 dataset is $1 \mathrm{hPa}$, it is difficult to undertake further investigation. A preliminary study using microwave limb sounder data indicates that the strong MASTJ first formed in the mesosphere and extended downward into the stratosphere. Therefore, analysis of the mesosphere is crucial for investigating the origin of this event, which will be done in a separate study. 
During the downward penetration of the middle atmospheric circulation change, stratospheric planetary waves deflected by the stronger MASTJ were trapped in the polar region and their amplitude increased over time (Fig. 3b). Some parts of wave packets propagating upward from the Eurasian sector were trapped in the lower stratosphere and troposphere, which led to amplification of a ridge over the North Pacific (Fig. 5). Further trapping of the wave resulted in amplification of the zonal wave number 1 component in the polar region. This trapping was also associated with the development in the troposphere of a trough over the Atlantic sector and a ridge over the Eurasian sector, leading to the formation of a blocking there. Such a change in the wave structure is similar to that observed following planetary wave reflection events (Shaw and Perlwitz, 2013; Kodera et al., 2008, 2013), although the pattern was somewhat shifted eastward in the present case. In the usual case, an initial change in the zonal-mean zonal wind field in the stratosphere is created by a stronger upward propagation of planetary waves from the troposphere (Kodera et al., 2016a). In the present case, reflection occurred without the preceding enhanced upward propagation of planetary waves from the troposphere, but it was attributed to the deflection of waves in the upper stratosphere by MASTJ.

The development of the MASTJ associated with the deflection of planetary waves (Fig. 5a) resulted in suppressed upwelling in the tropical stratosphere (Fig. 3f). According to the downward control principle (Haynes et al., 1991), momentum forcing induces meridional circulation below the level of the zone where the forcing is applied. In addition, the meridional extent of the induced circulation becomes wider than that of the forcing when a transient response is considered (Holton et al., 1995). In this respect, the wave forcing change related to the MASTJ should have a stronger impact on the tropics than that of the PNJ. If we focus on the tropics alone, the present strong MASTJ event was opposite to the SSW that induces enhanced tropical upwelling (Eguchi et al., 2015; Kodera et al., 2015). In addition, the temperature change in the troposphere was negligible during the present event, but the vertical velocity change penetrated farther into the TTL and troposphere due to interaction with clouds. Thus, it is expected that adiabatic heating due to the anomalous downwelling would be balanced by the induced diabatic cooling by cloud evaporation in the TTL (Figs. 6 and 7).

The impact of stratospheric circulation on the MJO has been reported in connection to the QBO (Kuma, 1990; Yoo and Son, 2016). The present results suggest that the change in TTL stability due to anomalous stratospheric downwelling had an impact on the sudden termination of the MJO event in early December 2011 (Fig. 10), opposite to the situation under an SSW event (Eguchi et al., 2015).

\section{Data availability}

Meteorological reanalysis and satellite observation data used in this paper are all publicly available. The JRA-55 dataset (Kobayashi et al., 2015) is available at http://jra.kishou.go.jp/JRA-55/index_en.html after registration. The CALIOP dataset (Winker et al., 2007) is available at https://eosweb.larc.nasa.gov/project/calipso/calipso_table. The EOS/MLS dataset (Livesey et al., 2015) is available at http://mirador.gsfc.nasa.gov/cgi-bin/ mirador/homepageAlt.pl?keyword=MLS. The OLR dataset (Arkin and Ardanuy, 1989) is available at http://www.esrl.noaa.gov/psd/data/gridded/data.interp_ OLR.html. The TRMM precipitation dataset (Huffman et al., 2007) can be obtained from GSFC/NASA at http://giovanni.gsfc.nasa.gov/giovanni/\#service $=$ TmAvMp $\&$ starttime $=\&$ endtime $=\&$ data $=$ TRMM_3B42_Daily_7 _precipitation \&variableFacets=dataProductPlatformInstrument 3ATRMM 3BdataProductTimeInterval 3Adaily 3B.

Acknowledgements. This work was supported in part by JSPS Grants-in-Aid for Scientific Research (S) JP2422401, (C) JP25340010, and (B) JP26287115. EOS/MLS and CALIOP data were from the Atmospheric Science Data Center (ASDC) at NASA. Analyses of TRMM data used in this paper were produced with the Giovanni online data system, developed and maintained by the NASA GES DISC.

Edited by: P. Haynes

Reviewed by: two anonymous referees

\section{References}

Andrews, D. G., Holton, J. R., and Leovy, C. B.: Middle Atmosphere Dynamics, Elsevier, New York, 489 pp., 1987.

Arkin, P. A. and Ardanuy, P. E.: Estimating climate-scale precipitation from space: A review, J. Climate, 2, 1229-1238, doi:10.1175/1520-0442(1989)002<1229:ECSPFS>2.0.CO;2, 1989.

Baldwin, M. P. and Dunkerton, T. J.: Propagation of the Arctic Oscillation from the stratosphere to the troposphere, J. Geophys. Res., 104, 30937-30946, doi:10.1029/1999JD900445, 1999.

Collimore, C. C., Martin, D. W., Hitchman, M. H., Huesmann, A., and Waliser, D. E.: On the relationship between the QBO and tropical deep convection, J. Climate, 16, 2552-2568, 2003.

Dunkerton, T. J.: Midwinter deceleration of the subtropical mesospheric jet and interannual variability of the high-latitude flow in UKMO analyses, J. Atmos. Sci., 57, 3838-3855, 2000.

Eguchi, N. and Kodera, K.: Impacts of stratospheric sudden warming event on tropical clouds and moisture fields in the TTL: a case study, SOLA, 6, 137-140, doi:10.2151/sola.2010-035, 2010.

Eguchi, N., Kodera, K., and Nasuno, T.: A global non-hydrostatic model study of a downward coupling through the tropical tropopause layer during a stratospheric sudden warming, Atmos. Chem. Phys., 15, 297-304, doi:10.5194/acp-15-297-2015, 2015. 
Eguchi, N., Kodera K., Funatsu, B., Takashima, H., and Ueyama, R.: Rapid convective transport of tropospheric air into the tropical lower stratosphere during the 2010 sudden stratospheric warming, SOLA, 12A, 13-18, doi:10.2151/sola.12A-003, 2016.

Gottschalck, J., Roundy, P. E., Schreck III, C. J., Vintzileos, A., and Zhang, C.: Large-scale atmospheric and oceanic conditions during the 2011-2012 DYNAMO field campaign, Mon. Weather Rev., 141, 4173-4196, 2013.

Hayashi, Y.: Vertical-zonal propagation of a stationary planetary wave packet, J. Atmos. Sci., 38, 1197-1205, doi:10.1175/15200469(1981)038<1197:VZPOAS>2.0.CO;2, 1981.

Haynes, P. H., Marks, C. J., McIntyre, M. E., Shepherd, T. G., and Shine, K. P.: On the "downward control" of extratropical diabatic circulations by eddy-induced mean zonal forces, J. Atmos. Sci., 48, 651-678, 1991.

Hitchcock, P., Shepherd, T. G., and Manney, G. L.: Statistical characterization of Arctic Polar-Night Jet Oscillation events. J. Climate, 26, 2096-2116, doi:10.1175/JCLI-D-12-00202.1, 2013.

Holton, J. R., Haynes, P., McIntyre, M., Douglass, A., Rood, R., and Pfister, L.: Stratosphere-troposphere exchange, Rev. Geophys., 33, 403-439, 1995.

Huffman, G. J., Bolvin, D. T., Nelkin, E. J., Wolff, D. B., Adler, R. F., Gu, G., Hong, Y., Bowman, K. P., and Stocker, E. F.: The TRMM Multisatellite Precipitation Analysis (TMPA): Quasiglobal, multiyear, combined-sensor precipitation estimates at fine scales, J. Hydrometeorol., 8, 38-55, 2007.

Iida, C., Hirooka, T., and Eguchi, N.: Circulation changes in the stratosphere and mesosphere during the stratospheric sudden warming event in January 2009, J. Geophys. Res.-Atmos., 119, 7104-7115, doi:10.1002/2013JD021252, 2014.

Kobayashi, S., Ota, Y., Harada, Y., Ebita, A., Moriya, M., Onoda, H., Onogi, K., Kamahori, H., Kobayashi, C., Endo, H., Miyaoka, K., and Takahashi, K.: The JRA-55 Reanalysis: general specifications and basic characteristics, J. Meteorol. Soc. Jpn., 93, 5-48, doi:10.2151/jmsj.2015-001, 2015.

Kodera, K.: Solar influence on the Indian Ocean Monsoon through dynamical processes, Geophys. Res. Lett., 31, L24209, doi:10.1029/2004GL020928, 2004.

Kodera, K.: Influence of stratospheric sudden warming on the equatorial troposphere, Geophys. Res. Lett., 33, L06804, doi:10.1029/2005GL024510, 2006.

Kodera, K. and Kuroda, Y.: Dynamical response to the solar cycle, J. Geophys. Res., 107, 4749, doi:10.1029/2002JD002224, 2002.

Kodera, K. and Shibata K.: Solar influence on the tropical stratosphere and troposphere in the northern summer, Geophys. Res. Lett., 33, L19704, doi:10.1029/2006GL026659, 2006.

Kodera, K., Mukougawa, H., and Itoh, S.: Tropospheric impact of reflected planetary waves from the stratosphere, Geophys. Res. Lett., 35, L16806, doi:10.1029/2008GL034575, 2008.

Kodera, K. Mukougawa, H., and Fujii, A.: Influence of the vertical and zonal propagation of stratospheric planetary waves on tropospheric blockings, J. Geophys. Res., 118, 1-13, doi:10.1002/jgrd.50650, 2013.

Kodera, K., Funatsu, B. M., Claud, C., and Eguchi, N.: The role of convective overshooting clouds in tropical stratospheretroposphere dynamical coupling, Atmos. Chem. Phys., 15, 67676774, doi:10.5194/acp-15-6767-2015, 2015.

Kodera, K., Mukougawa, H., Maury, P., Ueda, M., and Claud, C.: Absorbing and reflecting sudden stratospheric warming events and their relationship with tropospheric circulation, J. Geophys. Res.-Atmos., 121, 80-94, doi:10.1002/2015JD023359, 2016a.

Kodera, K., Thiéblemont, R., Yukimoto, S., and Matthes, K.: How can we understand the global distribution of the solar cycle signal on the Earth's surface?, Atmos. Chem. Phys., 16, 12925-12944, doi:10.5194/acp-16-12925-2016, 2016b.

Kuma, K.: A quasi-biennial oscillation in the intensity of the intraseasonal oscillation, Int. J. Climatol., 10, 263-278, 1990.

Kuroda, Y. and Kodera, K.: Role of planetary waves in the stratosphere-troposphere coupled variability in the Northern Hemisphere winter, Geophys. Res. Lett., 26, 2375- 2378, 1999.

Kuroda, Y. and Kodera, K.: Role of polar-night jet oscillation on the formation of the Arctic Oscillation in the northern hemisphere winter, J. Geophys. Res., 109, D11112, doi:10.1029/2003JD004123, 2004.

Liess, S. and Geller, M. A.: On the relationship between QBO and distribution of tropical deep convection, J. Geophys. Res., 117, D03108, doi:10.1029/2011JD016317, 2012.

Livesey, J. N., Read, W. G., Wagner, P. A., Froidevaux, L., Lambert, A., L., Manney, G., Millán Valle, L. F., Pumphrey, H. C., Santee, M. L., Schwartz, M. J., Wang, S., Fuller, R. A., Jarnot, R. F., Knosp, B. W., and Martinez, E.: Earth Observing System (EOS) Aura Microwave Limb Sounder (MLS) Version 4.2x Level 2 data quality and description document, JPLD-33509, available at: http://mls.jpl.nasa.gov/data/v4-2_data_quality_document.pdf (last access: 5 January 2017), 2015.

Lu, H., Gray, L. J., Jarvis, M. J., and Baldwin, M. P.: High and low frequency 11-year solar cycle signature in the Southern Hemispheric winter and spring, Q. J. Roy. Meteor. Soc., 137, 16411656, 2011.

Madden, R. A. and Julian, P. R.: Description of global-scale circulation cells in the tropics with a 40-50 day period, J. Atmos. Sci., 29, 1109-1123, 1972.

Marshall, G. J., Stott, P. A., Turner, J., Connolley, W. M., King, J. C., and Lachlan-Cope, T. A.: Causes of exceptional atmospheric circulation changes in the Southern Hemisphere, Geophys. Res. Lett., 31, L14205, doi:10.1029/2004GL019952, 2004.

Matsuno, T.: Vertical propagation of stationary planetary waves in the winter northern hemisphere, J. Atmos. Sci., 27, 871-883, 1970.

Nasuno, T.: Forecast skill of Madden-Julian Oscillation events in a global nonhydrostatic model during the CINDY2011/DYNAMO observation period, SOLA, 9, 69-73, doi:10.2151/sola.2013016, 2013.

Perlwitz, J. and Harnik, N.: Observational evidence of a stratospheric influence on the troposphere by planetary wave reflection, J. Climate, 16, 3011-3026, 2003.

Polvani, L. M., Waugh, D. W., Correa, G. J. P., and Son, S.-W.: Stratospheric ozone depletion: The main driver of twentiethcentury atmospheric circulation changes in the southern hemisphere, J. Climate, 24, 795-812, doi:10.1175/2010JCLI3772.1, 2011.

Shaw, T. A. and Perlwitz, J.: The life cycle of northern hemisphere downward wave coupling between the stratosphere and troposphere, J. Climate, 26, 1745-1763, 2013.

Thompson, D. W. J. and Solomon, S.: Interpretation of recent Southern Hemisphere climate change, Science, 296, 895-899, 2002. 
Thompson, D. W. J. and Wallace, J. M.: Regional climate impacts of the Northern Hemisphere annular mode, Science, 293, 85-89, 2001.

Wheeler, M. and Hendon, H.: An all-season real-time multivariate MJO Index: development of an index for monitoring and prediction, Mon. Weather Rev., 132, 1917-1932, doi:10.1175/15200493(2004)132<1917:AARMMI>2.0.CO;2, 2004.

Winker, D. M., Hunt, W. H., and McGill, M. J.: Initial performance assessment of CALIOP, Geophys. Res. Lett., 34, L19803, doi:10.1029/2007GL030135, 2007.
Yoden, S. and Ishioka, K.: A numerical experiment of the breakdown of polar vortex due to forced Rossby waves, J. Meteorol. Soc. Jpn., 71, 59-72, 1993.

Yoneyama, K., Zhang, C., and Long, C. N.: Tracking Pulses of the Madden-Julian Oscillation, B. Am. Meteorol. Soc., 94, 18711891, doi:10.1175/BAMS-D-12-00157.1, 2013.

Yoo, C. and Son, S.-W.: Modulation of the boreal wintertime Madden-Julian oscillation by the stratospheric quasibiennial oscillation, Geophys. Res. Lett., 43, 1392-1398, doi:10.1002/2016GL067762, 2016. 